\title{
Physico-Geometrical Kinetic Modeling of the Thermal Decomposition of Magnesium Hydroxide
}

Shun Iwasaki, Satoki Kodani, and Nobuyoshi Koga*

Chemistry Laboratory, Department of Science Education, Graduate School of Education, Hiroshima University, 11-1 Kagamiyama, Higashi-Hiroshima 739-8524, Japan.

\section{Contents}

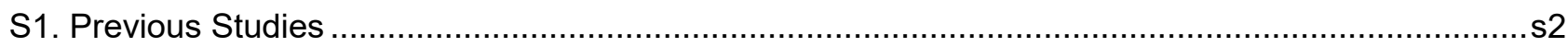

Table S1. Summary of previously reported kinetic results for the thermal decomposition of $\mathrm{Mg}(\mathrm{OH})_{2} \ldots \ldots \ldots \ldots . . . \mathrm{s} 2$

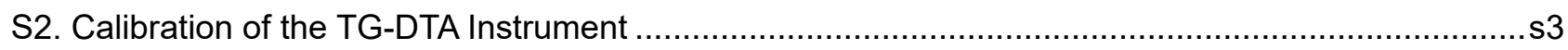

S3. Characterization of Sample and its Thermal Behavior .............................................................. 3

Figure S1. XRD pattern (a) and FT-IR spectrum (b) of the $\mathrm{Mg}(\mathrm{OH})_{2}$ sample.................................................s3

Figure S2. Typical SEM images of the $\mathrm{Mg}(\mathrm{OH})_{2}$ sample: (a) $\times 2,000$ and (b) $\times 10,000$ magnifications..............s3

Figure S3. Changes in the surface textures of the $\mathrm{Mg}(\mathrm{OH})_{2}$ sample after heating to different temperatures at $\beta=$ $3 \mathrm{~K} \mathrm{~min}^{-1}$ under a stream of dry $\mathrm{N}_{2}\left(300 \mathrm{~cm}^{3} \mathrm{~min}^{-1}\right)$ : (a) $513 \mathrm{~K}(\alpha=0.01)$, (b) $545 \mathrm{~K}(\alpha=0.12)$, (c) $577 \mathrm{~K}(\alpha=$ $0.66)$, (d) $588 \mathrm{~K}(\alpha=0.89)$, and (e) $600 \mathrm{~K}(\alpha=0.96)$.

Figure S4. Change in the specific surface area $\left(S_{\mathrm{BET}}\right)$ value of the $\mathrm{Mg}(\mathrm{OH})_{2}$ sample during the major mass-loss process of the thermal decomposition: (a) $S_{\mathrm{BET}}$ versus $T$ and (b) $S_{\mathrm{BET}}$ versus $\alpha$. ... 44

S4. Mathematical Deconvolution Analysis .54

Figure S5. Kinetic curves at various $\beta$ values for each reaction step of the thermal decomposition of the $\mathrm{Mg}(\mathrm{OH})_{2}$ sample under a stream of dry $\mathrm{N}_{2}$ gas, created using the MDA: (a) the first $(i=1)$ and (b) second $(i=2)$ reaction steps.

Figure S6. Results of the formal kinetic analysis for each reaction step of the thermal decomposition of the $\mathrm{Mg}(\mathrm{OH})_{2}$ sample under nonisothermal conditions, under a stream of dry $\mathrm{N}_{2}$ gas, separated using the MDA: (a) Friedman plots for the first reaction step $(i=1)$, (b) Friedman plots for the second reaction step $(i=2)$, (c) $E_{\mathrm{a}, i}$

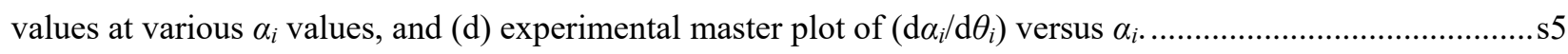

Table S2. Kinetic parameters determined by the formal kinetic analysis of each reaction step separated by MDA ...s6

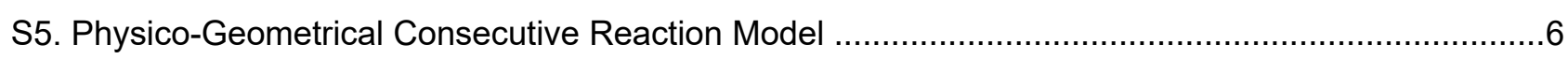

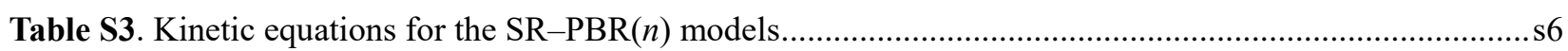

Table S4. Optimized rate constants for the SR-PBR $(n)$ models for the isothermal decomposition of the $\mathrm{Mg}(\mathrm{OH})_{2}$ sample at different temperatures under a stream of dry $\mathrm{N}_{2}$. ..s7

\footnotetext{
* Corresponding Author: e-mail: nkoga@hiroshima-u.ac.jp
} 


\section{Supporting Information}

\section{S1. Previous Studies}

Table S1. Summary of previously reported kinetic results for the thermal decomposition of $\mathrm{Mg}(\mathrm{OH})_{2}$

\begin{tabular}{|c|c|c|c|c|c|c|c|c|c|}
\hline \multirow{2}{*}{ Ref. } & \multirow{2}{*}{ Sample } & \multirow{2}{*}{ Particle Size } & \multirow{2}{*}{ Technique } & \multirow{2}{*}{ Condition } & \multirow{2}{*}{ Atmosphere } & \multirow{2}{*}{ Sample Mass } & \multirow{2}{*}{ Kinetic Model } & \multicolumn{2}{|c|}{ Kinetic Parameter } \\
\hline & & & & & & & & $E_{\mathrm{a}} / \mathrm{kJ} \mathrm{mol}^{-1}$ & $A / \mathrm{s}^{-1}$ \\
\hline 46 & Reagent & $\leq 5 \mu \mathrm{m}$ & TG & $\begin{array}{c}\text { Nonisothermal } \\
\left(\beta=5-25 \mathrm{~K} \mathrm{~min}^{-1}\right)\end{array}$ & $\begin{array}{c}\mathrm{N}_{2} \text { flow }\left(60 \mathrm{~cm}^{3}\right. \\
\left.\mathrm{min}^{-1}\right)\end{array}$ & $5 \mathrm{mg}$ & F1 & $141-149$ & $1.7 \times 10^{9}$ \\
\hline \multirow[t]{2}{*}{47} & \multirow[t]{2}{*}{ Synthetic } & \multirow{2}{*}{-----} & HT-XRD & $\begin{array}{c}\text { Isothermal } \\
(T=513-553 \mathrm{~K})\end{array}$ & \multirow{2}{*}{----} & \multirow{2}{*}{-----} & \multirow{2}{*}{$\begin{array}{l}\text { 1) } \alpha \leq 0.6: \mathrm{A} 3 \\
\text { 2) } 0.9 \leq \alpha \leq 1: \mathrm{A} 4\end{array}$} & $130-150$ & \multirow{2}{*}{----} \\
\hline & & & TG & $\begin{array}{c}\text { Nonisothermal } \\
\left(\beta=1-32 \mathrm{~K} \mathrm{~min}^{-1}\right)\end{array}$ & & & & $120-160$ & \\
\hline 48 & Reagent & ----- & CRTG & ----- & ----- & $30 \mathrm{mg}$ & A3 & $180-188$ & $9.5 \times 10^{13}$ \\
\hline \multirow[t]{2}{*}{49} & \multirow[t]{2}{*}{ Synthetic } & \multirow{2}{*}{120 mesh passed } & \multirow{2}{*}{ TG } & $\begin{array}{c}\text { Nonisothermal } \\
\left(\beta=10 \mathrm{~K} \mathrm{~min}^{-1}\right) \\
\end{array}$ & $\begin{array}{c}\text { Air flow } \\
\left(20-30 \mathrm{~cm}^{3} \mathrm{~min}^{-1}\right)\end{array}$ & \multirow{2}{*}{----- } & ---- & 145 & \multirow{2}{*}{-----} \\
\hline & & & & $\begin{array}{c}\text { Nonisothermal } \\
\left(\beta=5-20 \mathrm{~K} \mathrm{~min}^{-1}\right)\end{array}$ & Dry air or humid air & & $\mathrm{A} 2$ or $\mathrm{A} 1.5$ & $147-151$ & \\
\hline 50 & Synthetic & ----- & TG & $\begin{array}{c}\text { Isothermal } \\
(T=623-773 \mathrm{~K})\end{array}$ & $\mathrm{N}_{2}$ & $20 \mathrm{mg}$ & $\begin{array}{l}\text { 1) } 350^{\circ} \mathrm{C}: \mathrm{F} 1 \\
\text { 2) } 400^{\circ} \mathrm{C}: \mathrm{A} 2 \text { or } \mathrm{A} 3 \\
\text { 3) } 450^{\circ} \mathrm{C}: \mathrm{A} 2\end{array}$ & $45-86$ & ----- \\
\hline 51 & Reagent & ----- & TG & $\begin{array}{c}\text { Isothermal } \\
(T=973-1123 \mathrm{~K})\end{array}$ & Atmospheric pressure & ----- & $v=k[\mathrm{C}]^{0.55}$ & 51 & ----- \\
\hline \multirow[t]{2}{*}{52} & Reagent & \multirow[t]{2}{*}{----- } & \multirow[t]{2}{*}{ DTA } & \multirow{2}{*}{$\begin{array}{c}\text { Nonisothermal } \\
\left(\beta=10-20 \mathrm{~K} \mathrm{~min}^{-1}\right)\end{array}$} & \multirow[t]{2}{*}{ Static air } & \multirow[t]{2}{*}{$250 \mathrm{mg}$} & $\frac{(1-\alpha)^{4 / 3}}{\left[(1-\alpha)^{-1 / 3}-1\right]}$ & 199-208 & $70-74$ \\
\hline & Synthetic & & & & & & $\mathrm{F} 1$ or $\mathrm{A} 2$ & $88-230$ & $1.4 \times 10^{-1}-81$ \\
\hline 53 & Synthetic & 100 mesh passed & TG-DSC & $\begin{array}{l}\text { Nonisothermal } \\
\left(\beta=5 \mathrm{~K} \mathrm{~min}^{-1}\right) \\
\end{array}$ & Covered with a lid & $15 \mathrm{mg}$ & $(1-\alpha)^{1.6}$ & 222 & $(1.2-1.6) \times 10^{1}$ \\
\hline 54 & Brucite & $\begin{array}{l}\text { 1) Thick crystal } \\
\text { 2) Thin crystal } \\
\text { 3) Powder ( } 325 \\
\text { mesh passed) }\end{array}$ & TG & $\begin{array}{c}\text { Isothermal } \\
\text { Crystal: } T=573-647 \\
\mathrm{~K} \\
\text { Powder: } T=514-600 \\
\mathrm{~K}\end{array}$ & vacuum & ----- & $\begin{array}{l}\text { Crystal: R2 } \\
\text { Powder: F1 }\end{array}$ & $121-180$ & $10^{11}-10^{13}$ \\
\hline 55 & $\begin{array}{c}\text { Brucite } \\
\text { Synthetic } \\
\end{array}$ & ----- & TG & $\begin{array}{c}\text { Nonisothermal } \\
\left(\beta=5.4 \mathrm{~K} \mathrm{~min}^{-1}\right)\end{array}$ & ----- & $100 \mathrm{mg}$ & ----- & $\begin{array}{l}215 \\
238 \\
\end{array}$ & ----- \\
\hline \multirow[t]{3}{*}{41} & Synthetic & $\begin{array}{l}\text { Hexagonal discs } \\
(100 \mathrm{~nm})\end{array}$ & \multirow{3}{*}{ TG } & \multirow{3}{*}{$\begin{array}{c}\text { Isothermal } \\
(T=520-575 \mathrm{~K})\end{array}$} & \multirow{3}{*}{ vacuum } & \multirow{3}{*}{$50 \mathrm{mg}$} & & 115 & $0.5 \times 10^{10}$ \\
\hline & $\begin{array}{c}\text { Brucite } \\
\text { (Canadian) }\end{array}$ & $\begin{array}{c}\text { Thin platelet } \\
\text { crystals }\end{array}$ & & & & & $\mathrm{R} 2$ & 99 & $2.7 \times 10^{10}$ \\
\hline & $\begin{array}{c}\text { Brucite } \\
\text { (Rhodesian) }\end{array}$ & Platelet crystal & & & & & & 81 & $\sim 2 \times 10^{10}$ \\
\hline 56 & Synthetic & $80-150$ mesh & & Isothermal & & $400 \mathrm{mg}$ & & $52-115$ & \\
\hline & Brucite & $\begin{array}{l}\text { varying particle } \\
\text { size }\end{array}$ & TG & $(T=578-623 \mathrm{~K})$ & vacuum & $500 \mathrm{mg}$ & R3 & $88-115$ & \\
\hline
\end{tabular}




\section{S2. Calibration of the TG-DTA Instrument}

The three TG-DTA instruments (TG8120, TG/DTA220, and TG8121) used in this study were all constructed with a horizontally-arranged differential balance system and two balance beams of R-type thermocouple. These instruments were preliminarily calibrated with respect to sample temperature and mass-change value using the standard procedure. The sample temperature was calibrated using the extrapolated onset temperature of the DTA endothermic peak for the melting of pure metals (In, $\mathrm{Sn}, \mathrm{Pb}, \mathrm{Zn}, \mathrm{Al}$, and Ag, > 99.99\%, Nilaco), recorded at $\beta=5 \mathrm{~K} \mathrm{~min}^{-1}$ under a stream of dry He gas (flowrate: $200 \mathrm{~cm}^{3} \mathrm{~min}^{-1}$ ) for TG8120 and dry $\mathrm{N}_{2}$ gas (flowrate: $300 \mathrm{~cm}^{3} \mathrm{~min}^{-1}$ ) for TG/DTA220 and TG8121. The calibration of the mass-change value was carried out by the addition/removal of a $10 \mathrm{mg}$ standard weight to/from the sample holder, at room temperature, by opening the furnace. Subsequently, the accuracy of the mass-change value during heating of the sample was confirmed by the TG-DTA measurement for the thermal dehydration and decomposition of calcium oxalate monohydrate $(>99.9985 \%$, Alfa Aesar) performed by heating at $\beta=5 \mathrm{~K} \mathrm{~min}^{-1}$ under a stream of dry He gas (flowrate: $200 \mathrm{~cm}^{3} \mathrm{~min}^{-1}$ ) for TG8120 and dry $\mathrm{N}_{2}$ gas (flowrate: $300 \mathrm{~cm}^{3} \mathrm{~min}^{-1}$ ) for TG/DTA220 and TG8121. It was confirmed that the baseline drift in the TG signal during heating an empty Pt pan at $\beta=5 \mathrm{~K} \mathrm{~min}^{-1}$ from room temperature to 1223 $\mathrm{K}$ was less than $\pm 25 \mu \mathrm{g}$ in all of the TG-DTA instruments.

For the measurements of the TG-DTA curves using TG/DTA220 and TG8121, approximately $3.0 \mathrm{mg}$ of $\mathrm{Al}_{2} \mathrm{O}_{3}(>99.99 \%)$ weighed in a $\mathrm{Pt}$ pan $(5 \mathrm{~mm}$ in diameter and $2.5 \mathrm{~mm}$ in height) was used as the reference material for DTA and the counter balance for TG. For the TG/DTA-MS measurement using TG8120, an empty Pt pan was used as the reference material and counter balance to avoid any possible release of gases from the reference material. For the TG curves recorded using the TG8121 for the kinetic calculation, the repeatability of the TG curves was confirmed for each measurement condition. Before converting to kinetic data, baseline correction was performed for all the mass-change curves for the sample using a blank data recorded under the same conditions.

\section{S3. Characterization of Sample and its Thermal Behavior}
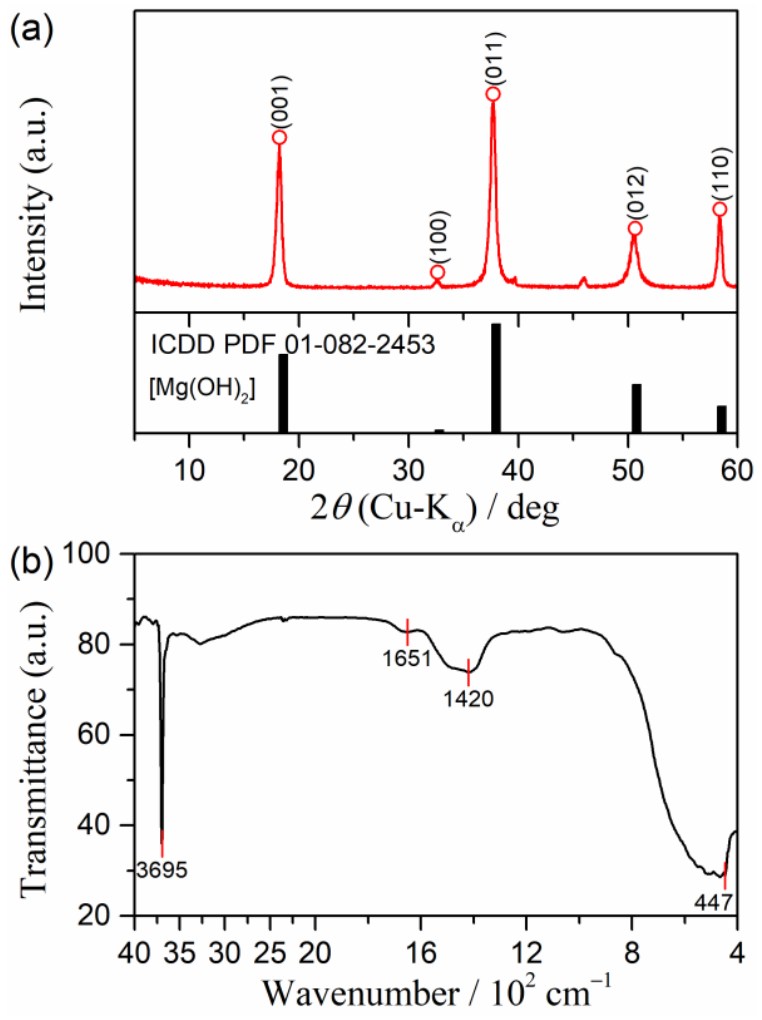

Figure S1. XRD pattern (a) and FT-IR spectrum (b) of the $\mathrm{Mg}(\mathrm{OH})_{2}$ sample.
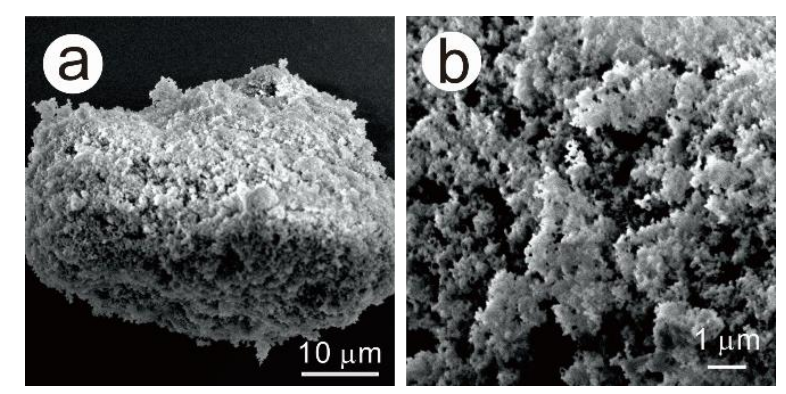

Figure S2. Typical SEM images of the $\mathrm{Mg}(\mathrm{OH})_{2}$ sample: (a) $\times 2,000$ and (b) $\times 10,000$ magnifications. 

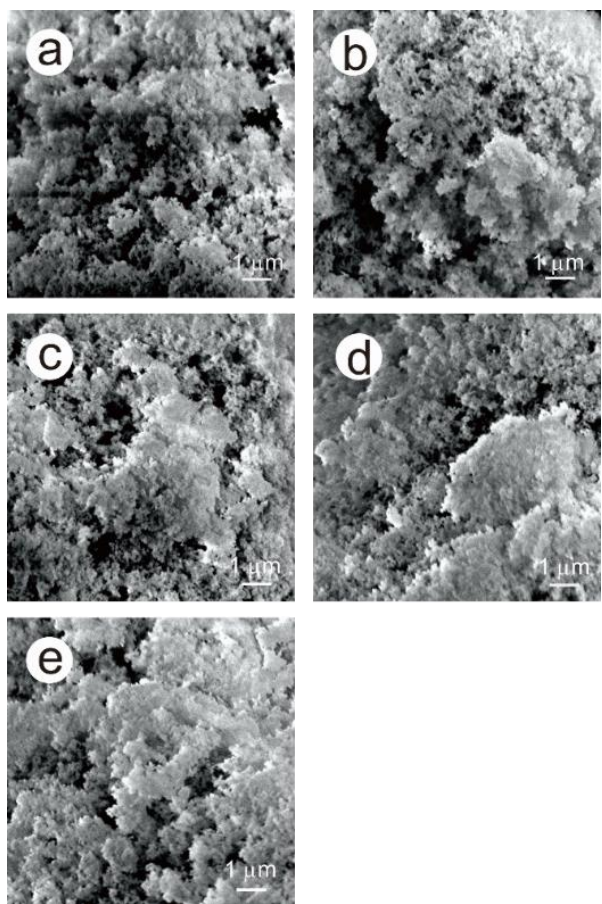

Figure S3. Changes in the surface textures of the $\mathrm{Mg}(\mathrm{OH})_{2}$ sample after heating to different temperatures at $\beta=3 \mathrm{~K} \mathrm{~min}^{-1}$ under a stream of dry $\mathrm{N}_{2}\left(300 \mathrm{~cm}^{3}\right.$ $\left.\min ^{-1}\right)$ : (a) $513 \mathrm{~K}(\alpha=0.01)$, (b) $545 \mathrm{~K}(\alpha=0.12)$, (c) $577 \mathrm{~K}(\alpha=0.66)$, (d) $588 \mathrm{~K}(\alpha=0.89)$, and (e) $600 \mathrm{~K}$ $(\alpha=0.96)$.
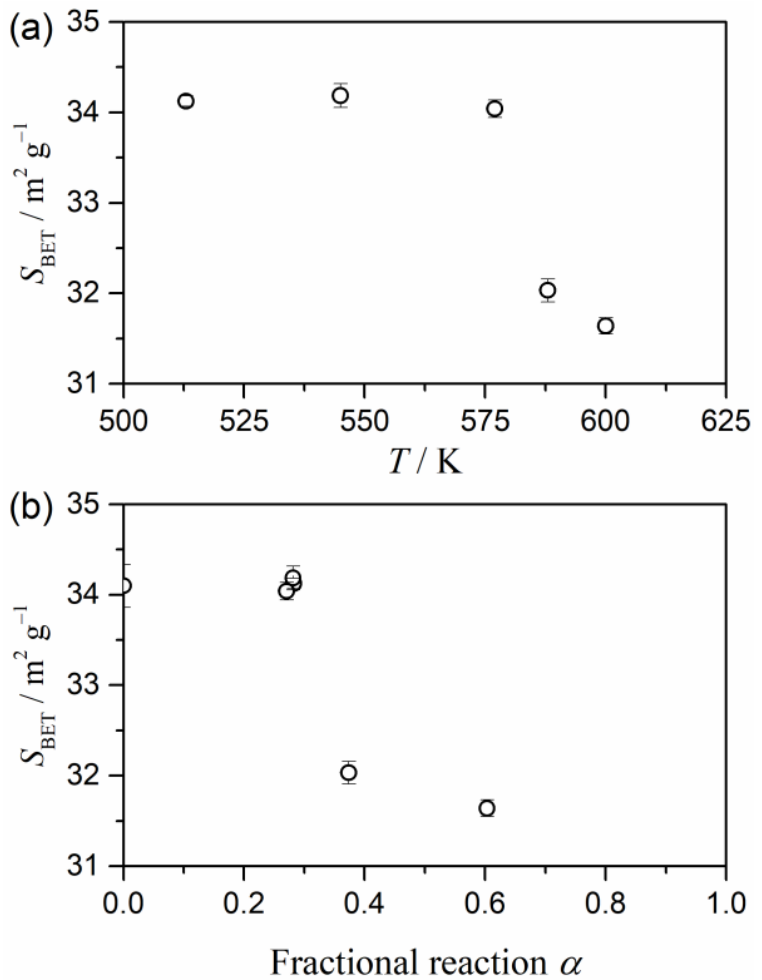

Figure S4. Change in the specific surface area $\left(S_{\mathrm{BET}}\right)$ value of the $\mathrm{Mg}(\mathrm{OH})_{2}$ sample during the major massloss process of the thermal decomposition: (a) $S_{\mathrm{BET}}$ versus $T$ and (b) $S_{\text {BET }}$ versus $\alpha$.

\section{S4. Mathematical Deconvolution Analysis}

(1) Statistical function used for the mathematical deconvolution analysis

The Weibull function was selected as one of the appropriate functions to separate the overall DTG peak into two reaction peaks.

$$
\begin{gathered}
F(t)=a_{0}\left(\frac{a_{3}-1}{a_{3}}\right)^{\frac{1-a_{3}}{a_{3}}}\left\{\frac{t-a_{1}}{a_{2}}+\left(\frac{a_{3}-1}{a_{3}}\right)^{\frac{1}{a_{3}}}\right\}^{a_{3}-1} \\
\times \exp \left[-\left\{\frac{t-a_{1}}{a_{2}}+\left(\frac{a_{3}-1}{a_{3}}\right)^{\frac{1}{a_{3}}}\right\}^{a_{3}}+\frac{a_{3}-1}{a_{3}}\right]
\end{gathered}
$$

where $a_{0}-a_{3}$ are parameters for describing amplitude, center, width, and shape, respectively.

(2) Formal kinetic analysis of the kinetic curves of each reaction step

Figure $\mathrm{S} 5$ shows the kinetic curves at various $\beta$ values for each reaction step of the thermal decomposition of the $\mathrm{Mg}(\mathrm{OH})_{2}$ sample under a stream of dry $\mathrm{N}_{2}$ gas, created via the mathematical deconvolution analysis (MDA). Irrespective of the reaction step, the kinetic curve shifts systematically to higher temperatures with increasing $\beta$ value, exhibiting this fundamental feature as a series of the kinetic curves. Figure S6 shows the results of the formal kinetic analysis applied to kinetic data obtained by the MDA. The Friedman plots generally indicate statistically significant linear correlation between $\ln \left(\mathrm{d} \alpha_{i} / \mathrm{d} t\right)$ and $T^{-1}$ with a correlation coefficient, $\gamma$, better than -0.99 (Figures S6(a) and (b)). The $E_{\mathrm{a}, 1}$ value for the first reaction step was nearly constant during the course of the reaction, whereas a slight increase as the reaction advanced was observed for the $E_{\mathrm{a}, 2}$ value for the second reaction step (Figure S6(c)). The average $E_{\mathrm{a}, i}$ values for $0.1 \leq \alpha_{i} \leq 0.9$ were calculated to be $\left(E_{\mathrm{a}, 1}, E_{\mathrm{a}, 2}\right)=(127.4 \pm 2.2,136.8 \pm 6.5)$ $\mathrm{kJ} \mathrm{mol}^{-1}$. The experimental master plot, drawn according to eq. (4), indicated the maximum $\mathrm{d} \alpha_{i} / \mathrm{d} \theta_{i}$ value midway through the reaction for both reaction steps, where $\mathrm{d} \alpha_{i} / \mathrm{d} \theta_{i}$ value had the order of $10^{9} \mathrm{~s}^{-1}$ (Figure S6(d)). Table S2 summarizes the apparent 
kinetic parameters determined by the formal kinetic analysis of mathematically separated kinetic curves of each reaction step.
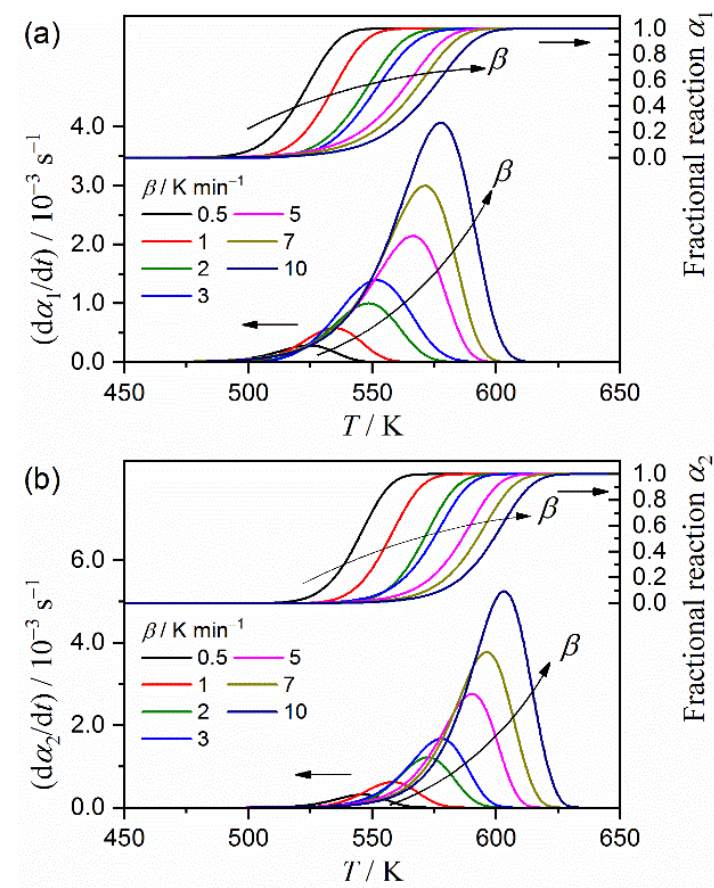

(a)
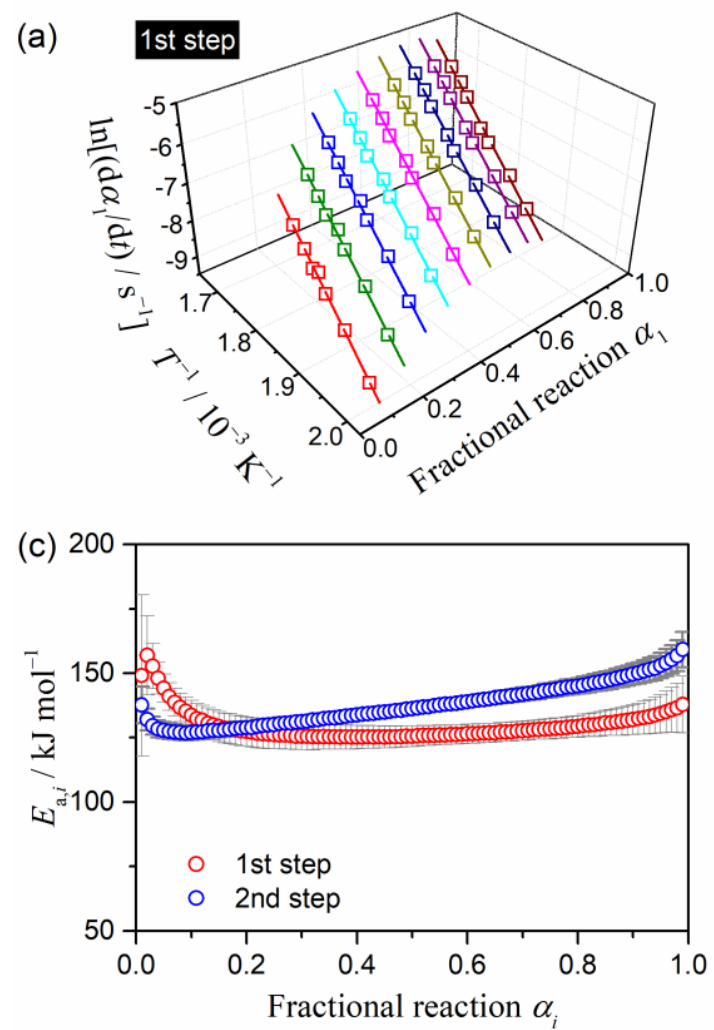

Figure S5. Kinetic curves at various $\beta$ values for each reaction step of the thermal decomposition of the $\mathrm{Mg}(\mathrm{OH})_{2}$ sample under a stream of dry $\mathrm{N}_{2}$ gas, created using the MDA: (a) the first $(i=1)$ and (b) second $(i=$ 2) reaction steps. (b)
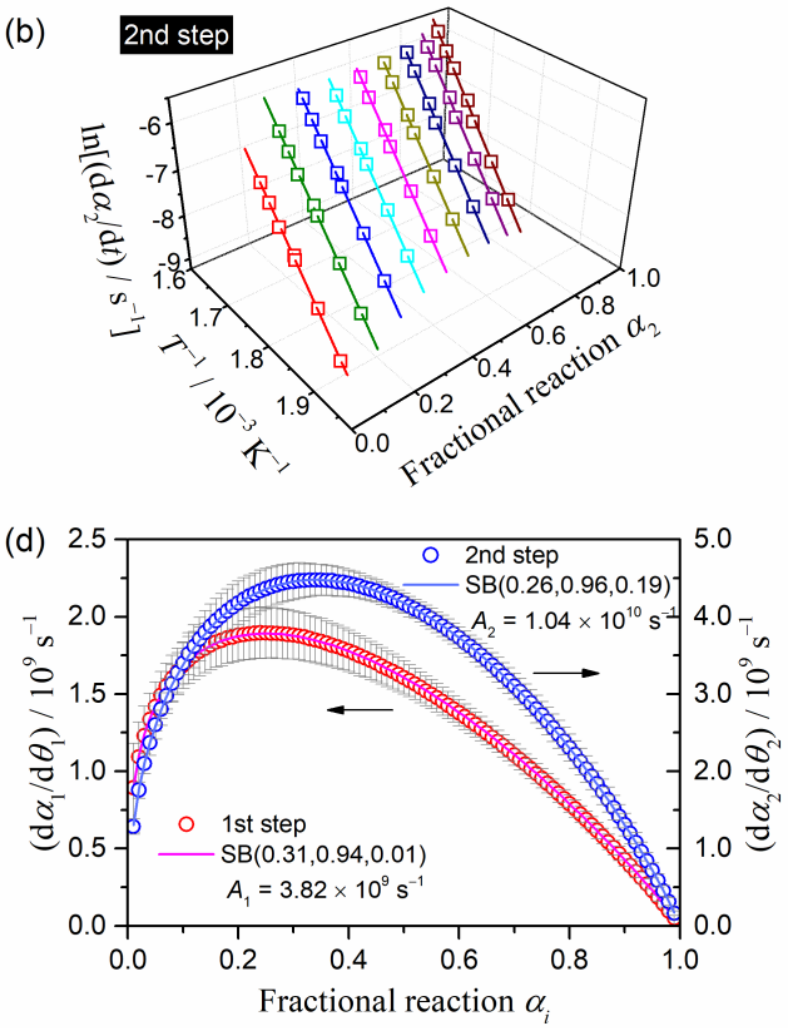

Figure S6. Results of the formal kinetic analysis for each reaction step of the thermal decomposition of the $\mathrm{Mg}(\mathrm{OH})_{2}$ sample under nonisothermal conditions, under a stream of dry $\mathrm{N}_{2}$ gas, separated using the MDA: (a) Friedman plots for the first reaction step ( $i=1$ ), (b) Friedman plots for the second reaction step $(i=2)$, (c) $E_{\mathrm{a}, i}$ values at various $\alpha_{i}$ values, and (d) experimental master plot of $\left(\mathrm{d} \alpha_{i} / \mathrm{d} \theta_{i}\right)$ versus $\alpha_{i}$. 


\section{Supporting Information}

Table S2. Kinetic parameters determined by the formal kinetic analysis of each reaction step separated by MDA

\begin{tabular}{|c|c|c|c|c|c|c|}
\hline \multirow{2}{*}{$i$} & \multirow{2}{*}{$c_{i}$} & \multirow{2}{*}{$E_{\mathrm{a}, i}^{\mathrm{a}} / \mathrm{kJ} \mathrm{mol}^{-1}$} & \multirow{2}{*}{$A_{i} / \mathrm{s}^{-1}$} & \multicolumn{3}{|l|}{$\mathrm{SB}\left(m_{i}, n_{i}, p_{i}\right)$} \\
\hline & & & & $m_{i}$ & $n_{i}$ & $p_{i}$ \\
\hline 1 & $0.29 \pm 0.03$ & $127.4 \pm 2.2$ & $(3.82 \pm 0.01) \times 10^{9}$ & $0.31 \pm 0.02$ & $0.94 \pm 0.01$ & $0.01 \pm 0.01$ \\
\hline 2 & $0.71 \pm 0.03$ & $136.8 \pm 6.5$ & $(1.04 \pm 0.01) \times 10^{10}$ & $0.26 \pm 0.02$ & $0.96 \pm 0.01$ & $0.19 \pm 0.02$ \\
\hline
\end{tabular}

${ }^{\text {a }}$ Average in the range of $0.1 \leq \alpha \leq 0.9$.

\section{S5. Physico-Geometrical Consecutive Reaction Model}

Table S3. Kinetic equations for the SR-PBR $(n)$ models

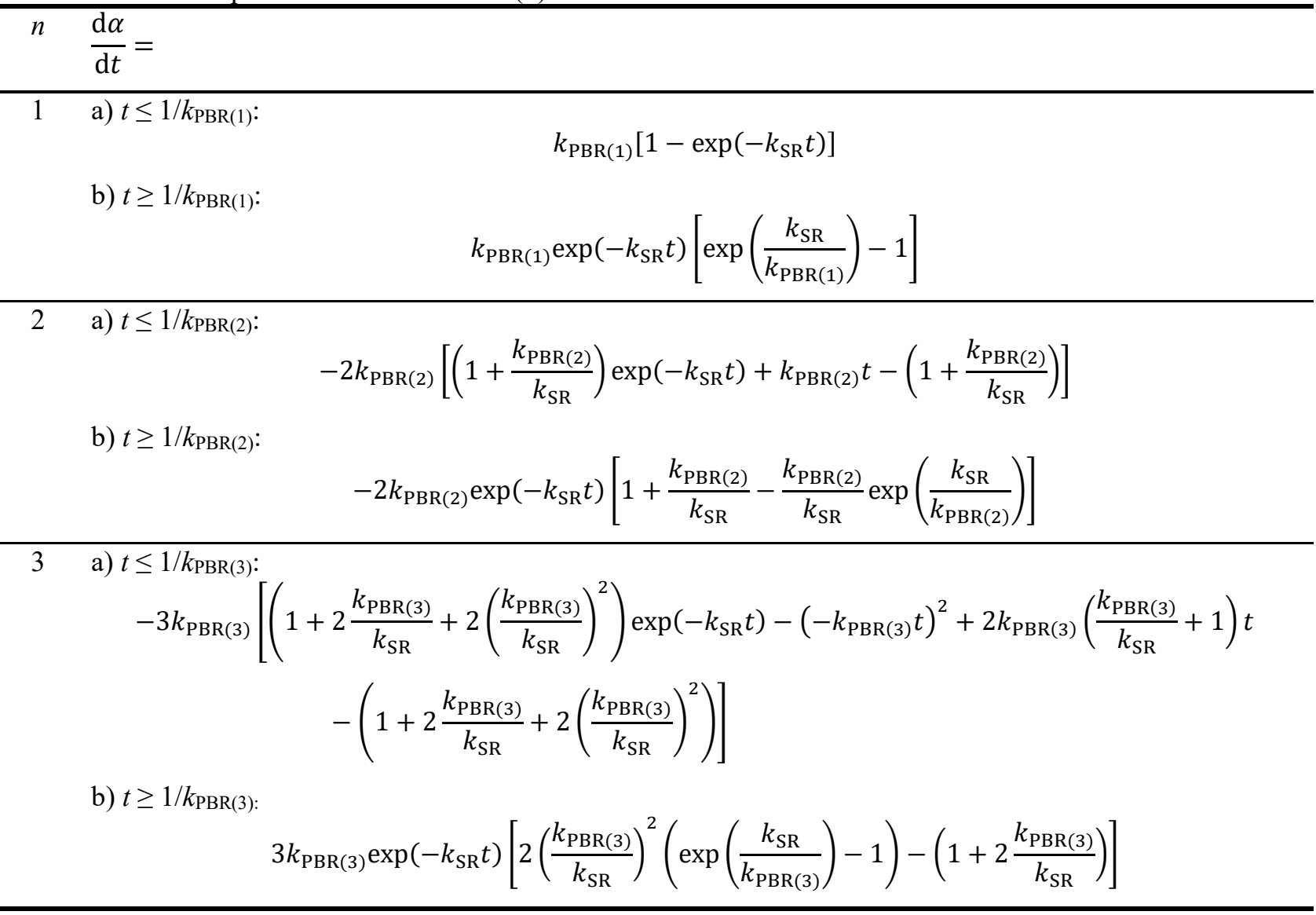




\section{Supporting Information}

Table S4. Optimized rate constants for the SR-PBR $(n)$ models for the isothermal decomposition of the $\mathrm{Mg}(\mathrm{OH})_{2}$ sample at different temperatures under a stream of dry

\section{$\mathrm{N}_{2}$}

\begin{tabular}{|c|c|c|c|c|c|c|c|c|}
\hline \multirow{3}{*}{$\begin{array}{l}\text { Model } \\
T \text { / K }\end{array}$} & \multicolumn{4}{|l|}{ SR-PBR(2) } & \multicolumn{4}{|l|}{ SR-PBR(3) } \\
\hline & \multirow{2}{*}{$k_{\mathrm{SR}} / 10^{-4} \mathrm{~s}^{-1}$} & \multirow{2}{*}{$k_{\mathrm{PBR}(2)} / 10^{-3} \mathrm{~s}^{-1}$} & \multicolumn{2}{|c|}{$\mathrm{R}^{2, *}$} & \multirow{2}{*}{$k_{\mathrm{SR}} / 10^{-4} \mathrm{~s}^{-1}$} & \multirow{2}{*}{$k_{\mathrm{PBR}(3)} / 10^{-3} \mathrm{~s}^{-1}$} & \multicolumn{2}{|c|}{$\mathrm{R}^{2, *}$} \\
\hline & & & differential & integral & & & differential & integral \\
\hline 539.4 & 3.33 & 3.09 & 0.9986 & 0.9993 & 3.35 & 2.29 & 0.9989 & 0.9994 \\
\hline 542.3 & 3.96 & 4.27 & 0.9969 & 0.9949 & 3.97 & 3.22 & 0.9970 & 0.9950 \\
\hline 545.4 & 4.65 & 6.07 & 0.9991 & 0.9996 & 4.66 & 4.70 & 0.9991 & 0.9996 \\
\hline 548.5 & 5.50 & 8.29 & 0.9968 & 0.9955 & 5.51 & 6.26 & 0.9968 & 0.9956 \\
\hline 551.5 & 6.59 & 9.95 & 0.9978 & 0.9985 & 6.60 & 7.70 & 0.9978 & 0.9985 \\
\hline 554.7 & 7.49 & 14.4 & 0.9976 & 0.9984 & 7.50 & 11.2 & 0.9976 & 0.9984 \\
\hline 557.8 & 8.67 & 20.1 & 0.9969 & 0.9984 & 9.19 & 14.4 & 0.9953 & 0.9990 \\
\hline
\end{tabular}

* Determination coefficient of the nonlinear least squares analysis. 